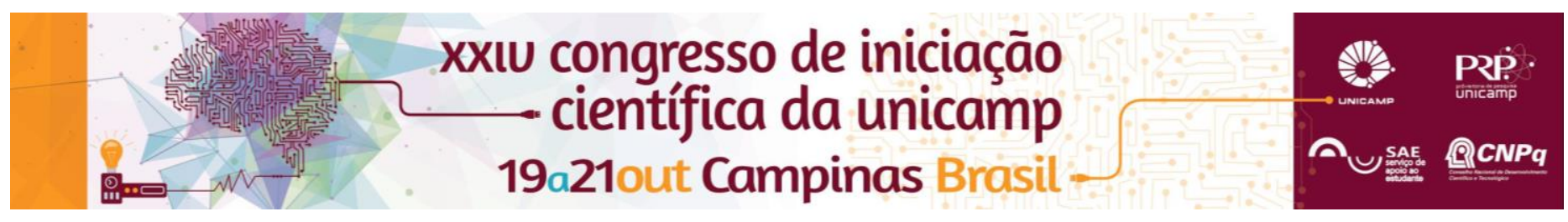

\title{
O IMPACTO DA FRAGILIDADE DO IDOSO NA EVOLUÇÃO PÓS-OPERATÓRIA DE PACIENTES COM CÂNCER GÁSTRICO
}

\author{
Paula Veri Guimarães*, Luiz Roberto Lopes.
}

\section{Resumo}

O envelhecimento da população tem levado a um aumento no número absoluto nos casos de cancer gástrico, bem como um impacto na saúde do idoso, pelo declínio de suas reservas funcionais e aumento do grau de dependência. Diversos escores de fragilidade foram criados para avaliar e categorizar a influência dessas variáveis na morbimortalidade da população idosa. O objetivo deste estudo foi correlacionar as medidas de fragilidade com a evolução pós operatória dos idosos submetidos a cirurgia para tratamento curativo do câncer gástrico.

Palavras-chave: Fragilidade do idoso, câncer gástrico, pós-operatório

\section{Introdução}

O câncer gástrico é atualmente a quinta principal neoplasia em ambos os sexos e a terceira causa de óbitos relacionados ao câncer. Apesar da tendência de queda da incidência nos últimos anos, com o envelhecimento da população, em números absolutos o câncer gástrico tem grande impacto na morbimortalidade geral.

O envelhecimento leva a uma série de mudanças no organismo, levando ao declínio da função de órgãos que tem como consequência a redução da reserva funcional do indivíduo. Associado ao aumento da prevalência de doenças crônicas na população idosa e ao aumento da dependência funcional, o envelhecimento da população pode ter grande impacto no tratamento de um paciente, bem como na sua evolução pós-operatória.

Devido à discordância entre a idade cronológica e o real estado de saúde do paciente, foram criadas diversas medidas de fragilidade do idoso, afim de melhor avaliar o grau de debilidade do paciente.

O objetivo deste trabalho é avaliar o impacto da fragilidade do idoso pelo Cardiovascular Health Study $(\mathrm{CHS})^{1}$ na evolução pós operatória de pacientes com câncer gástrico submetidos a cirurgia com proposta curativa.

\section{Resultados e Discussão}

Foram avaliados quinze pacientes com diagnóstico de câncer gástrico e proposta de cirurgia como tratamento curativo. No pré-operatório foi realizada a avaliação da fragilidade do idoso segundo os critérios do $\mathrm{CHS}$ - perda de peso, exaustão, diminuição da velocidade de marcha, fraqueza, avaliada pela diminuição da força de preensão palmar e grau de atividade física. Após a cirurgia foram avaliadas a presença de complicações, como fístulas, deiscência de sutura e anastomoses, infecções, tanto no pós-operatório imediato, quanto no tardio - avaliado em média de três a seis meses após o ato cirúrgico.

Tabela 1. Classificação dos pacientes avaliados $(n=15)$

\begin{tabular}{|c|c|c|}
\hline Não Frágil & Pré-Fragil & Frágil \\
\hline $33,3 \%$ & $26,6 \%$ & $40 \%$ \\
\hline
\end{tabular}

Não Frágil - ausência de critérios, Pré-fragil - 1 ou 2 critérios e Frágil - 3 ou mais critérios.

Dos quinze pacientes avaliados, três (20\%) no ato cirúrgico foram diagnosticados com metástases intraabdominais, sendo optado por não realizar ressecção do tumor, apenas gastroenteroanastomose ou biópsia de implantes da cavidade. Dos pacientes que se enquadraram nessa situação, um deles foi classificado como não frágil e os outros dois como frágeis.

Dos doze pacientes submetidos à ressecção tumoral, $25 \%$ dos casos foram submetidos à gastrectomia total e nos outros $75 \%$ subtotal, a depender do local da lesão. Desses, dois pacientes foram também diagnosticados com implantes tumorais intra-abdominais no resultado do estudo anatomopatológico. Ambos classificados anteriormente no grupo dos frágeis.

Dos doze pacientes submetidos à gastrectomia subtotal ou total - apenas um paciente apresentou complicação no pós-operatório imediato, com bridas, fístula da enteroanastomose e fistula entero-cutânea, sendo este classificado como não frágil. Todos os demais pacientes apresentaram boa evolução no pósoperatório imediato e tardio, sem complicações.

Assim, do grupo dos pacientes previamente classificados como frágeis, 33,3\% não foi submetido à ressecção tumoral por diagnóstico de metástase no inventário da cavidade, e os demais $66,6 \%$ foram submetidos à ressecção sem complicações no pós-operatório embora 33,3\% destes tenham sido também diagnosticados com metástases no resultado do anatomopatológico. Do grupo dos pré-frágeis $100 \%$ foram submetidos à ressecção tumoral, sem complicações no pós-operatório imediato e tardio. E do grupo dos não frágeis, $20 \%$ não foi submetido à ressecção, $20 \%$ evoluiu com fístulas no pós-operatório imediato e $60 \%$ evoluiu sem complicações.

\section{Conclusões}

Embora a fragilidade no idoso seja um maior preditor de morbidade e mortalidade pela diminuição das reservas funcionais e maior grau de dependência, a partir dos resultados obtidos, não foi observada correlação entre o estado de fragilidade e a evolução com complicações no pós-operatório. Esse resultado pode ser um indicativo que o preparo adequado dos pacientes no pré-operatório, os cuidados clínicos no pós-operatório imediato e o seguimento no pós-operatório tardio protocolados pelo nosso serviço, foram capazes de minimizar os efeitos que a fragilidade do idoso teriam sobre uma evolução desfavorável.

1 Fried, LP; Tangen, CM; Walston, J; Newman, AB; Hirsch, C; Gottdiener, J; Seeman, T; Tracy, R; Kop, WJ; Burke, G; McBurnie, MA; Cardiovascular Health Study Collaborative Research Group. Frailty in older adults: evidence for a phenotype.J Gerontol A Biol Sci Med Sci. 2001; 56(3):M146. 